\title{
THE APPLICATION OF GIS IN TOURISM PLANNING AND SUSTAINABLE TOURISM DEVELOPMENT
}

\author{
Alma Pobrić ${ }^{1}$ \\ Amina Sivac ${ }^{2}$
}

\begin{abstract}
Tourism planning is a complex process that includes the involvement of a number of factors during the process of decision-making. Taking into account that any rational planning of tourism should be in line with the principles of sustainable development, which means to preserve the physical and social-geographical attributes of a destination, but at the same time striking a balance with the interests of the local communities, private and public sectors, the use of geographic information systems (GIS) has become an imperative in the process. Tourism is an activity which depends on natural resources, but is also a phenomenon which can have a destructive effect on the natural geographic environment in case of an inadequate access to its planning and development. In addition, during the daily management and operations of tourist facilities, a large number of tourists are a big consumer of energy and water and at the same time produce a significant amount of solid waste, hazardous gases and waste water. These negative impacts of tourism can be prevented or reduced by the application of certain GIS technology in order to achieve sustainable tourism development. This papers main objective is to explore the potential of GIS application in a process of tourism planning and its sustainable development, for the purpose of long-term survival of the tourism destination.
\end{abstract}

Keywords: GIS, tourism, tourism planning, sustainable development

\section{INTRODCTION}

Tourism planning is a complex process that includes the involvement of a number of factors during the process of decision-making. Any rational planning of tourism should be in line with the principles of sustainable development, which means to preserve the physical and social-geographical attributes of a destination, at the same time striking a balance with the interests of the local communities, private and public sectors. Therefore, the use of geographic information systems (GIS) has become an imperative in the process.

Geographic Information System (GIS) is one of the most important technological innovations in the process of tourism planning and decision-making for the further development of tourism. It is defined as "a system for collecting, storing, checking, integrating, managing, analyzing and displaying data which are spatially associated with the Earth" (Burrough, McDonnell, 1998.), which usually includes spatial databases and related applications. GIS is used in many sciences and scientific disciplines, notably geography, regional and spatial planning and environmental protection, but also in economics, anthropology, archeology and other sciences where tourism is of interest.This is because it's a valuable tool for managing, analyzing and displaying data related to the local and regional levels of the various activities. A huge advantage of GIS is to enable the

\footnotetext{
${ }^{1}$ Assistant Professor, Department of Geography, Faculty of Science, University of Sarajevo, Sarajevo, Bosnia and Herzegovina.

${ }^{2}$ Teaching Assistant, Department of Geography, Faculty of Science, University of Sarajevo, Sarajevo, Bosnia and Herzegovina.
} 
inclusion of all stakeholders who are included in the tourism development process of a certain area. GIS can unite the point of view of state institutions, NGOs, private companies and organizations. Based on the views of all relevant stakeholders, it can help them to make the best decisions for the development of tourism in a particular area.

\section{SOME POSSIBILITIES OF GIS APPLICATION IN TOURISM PLANNING AND SUSTAINABLE TOURISM DEVELOPMENT}

Tourism is an activity which depends on natural resources, but is also a phenomenon which can have a destructive effect on the natural geographic environment in case of an inadequate access to its planning and development. Negative impacts of tourism on the environment are manifested primarily through its degradation bythe mass tourist visits and the construction of tourism infrastructure in inadequate areas. In addition, during the daily management and operations of tourist facilities, a large number of tourists are a big consumer of energy and water and at the same time produce a significant amount of solid waste, hazardous gases and waste water.

These negative impacts can be prevented or reduced by the application of certain GIS technology in order to achieve sustainable tourism development. Main applications of GIS in planning and management of sustainable development of tourism include the following activities:

- inventory of natural and cultural resources of a destination;

- determining the shortest path between two or more places;

- planning and determining the appropriate location for the development of tourism;

- promotion of a tourist destination;

- determiningpaths and attractions suitable for sustainable tourism.

\section{Inventory of natural and cultural resources of a destination}

An inventory of tourism resources primarily involves creating a database of the physical geographical and social-geographical tourism resources of a destination, but also including the data of tourism infra and superstructure, demographics, etc.

The next step is digitizing all or some of the items listed above and their integration into a single interactive map connected to a previously made database. An example is shown in Fig. 1. This database can contain various information - from basic data about the attraction to its detailed description, possible times of visits, the ticket price etc.

After the user selects one and/or more objects in the database, it will automatically be highlighted on the accompanying interactive map and vice versa. This enables the user to obtain more information about the location and characteristics of specific attractions, thereby enabling easier selection of the desired route and the places of interest. 


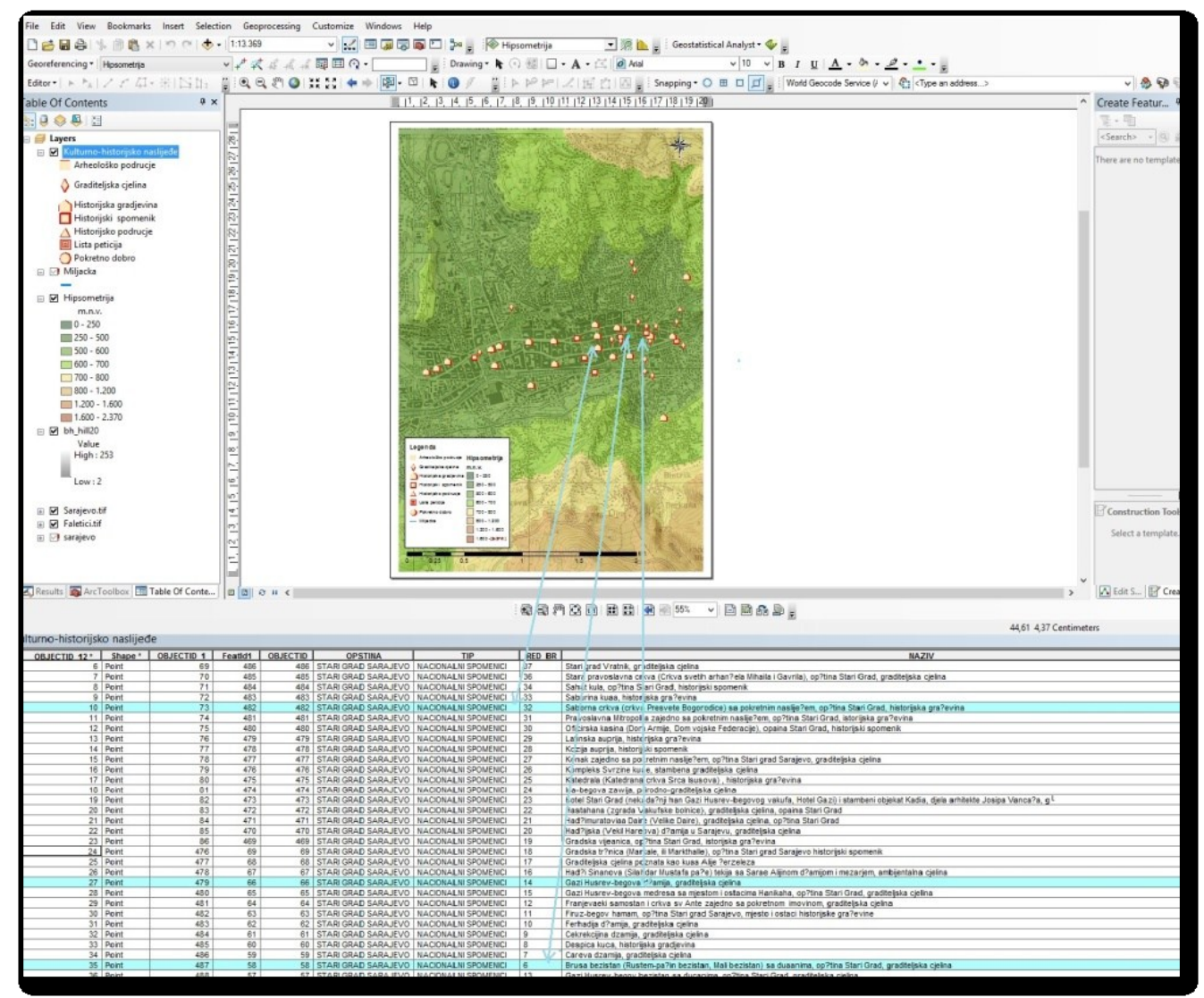

Fig. 1. GIS database and map of cultural heritage in downtown Sarajevo with tourist information included

\section{Determining the shortest path between two or more places}

Determining the shortest or the most suitable path between two or more attractions is the part of the GIS which is mostly used by the destination visitors. Users can establish a tourist route with landing points by their own choice, where GIS provides them the information on the distance between the selected attractions, shortest relation between them etc. 


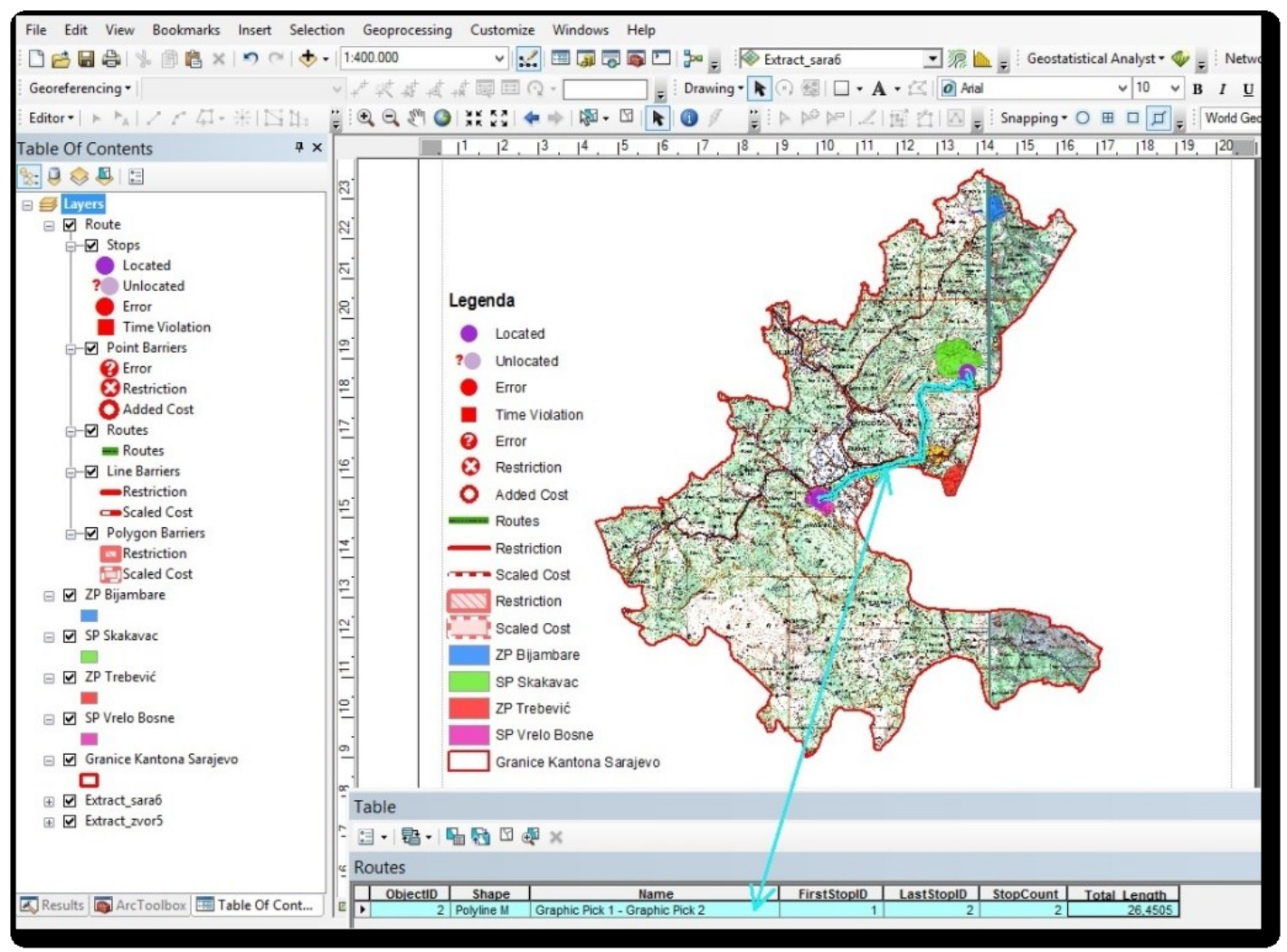

Fig. 2. The shortest route plan from PA VreloBosne to PA Skakavac in Sarajevo Canton

Users can also plan routes for an entire journey, calculate drive-times, locate facilities and solve other network related problems. On the other hand, the management of tourist destinationscan use this option to create their own itineraries and offer them to visitors. All of this can be done by a part of the ArcGIS called Network Analyst, which provides users network-based spatial analysis tools for solving complex routing problems. It uses a configurable transportation network data model, allowing users to accurately represent their unique network requirements.

\section{Planning and determining the appropriate location for the development of tourism}

The planning and determination of appropriate sites for tourism development is one of the most important functions of GIS in terms of tourism planning. Creating a database for morphometric characteristics (the morphometric features of the terrain, the horizontal and vertical articulation of relief, slope and elevation of the terrain, exposure, etc.), exogenously-geomorphological, hydrological and soil characteristics and their cartographic representation, is the basis for all the future activities in terms of tourism planning.

This involves determining the most suitable location for building new touristic sites and infrastructure or the renewal of existingones, planning new zones to practice various forms of tourism activities and the determination of the maximum allowable number of tourists in a particular area for a purpose of a sustainable development. The measurement and 
monitoring of tourism impacts would include the registration of changes in destinations brought by tourism development. This enables the assessment of the advantages and disadvantages brought by tourism, and also a good basis for all the future activities.

\section{Promotion of a tourist destination}

The promotion of a tourist destination by using GIS involves the synthesis of the results of the inventory of tourism resources process, their mapping and presentingthem to the tourists through a website aimed at the tourist promotion of an area. Promotion via the Internet has become an obligation for all decision makers in the process of tourism planning and development, such as public authorities and organizations responsible for tourism and the relevant ministries and tourism organizations.

Given that tourism has a very strong geographical component, the use of geographic maps is of the utmost importance in the process of thepromotion of a destination. GIS can also be useful to identify areas that have the best profit potential. For example, data on the frequency of traffic in certain areas within the destination may affect the values of defining specific locations for the placement of promotional materials such as billboards.

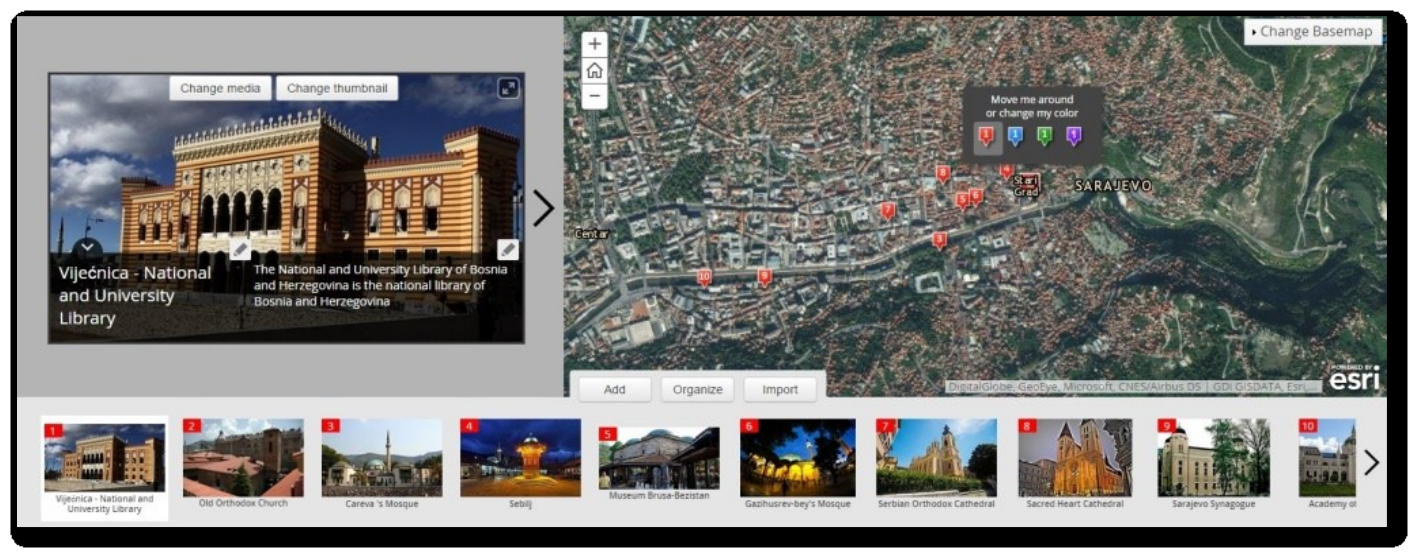

Fig. 3. A story map of downtown Sarajevo with multimedia content included

As a part of ArcGIS, Esri Story Maps lets users use the full power of the world's leading mapping and GIS platforms to create their own maps. This is particularly important for the management of tourist destinations, although it can be used by local community members who would like to promote their local attractions as well. Esri Story Maps letsusers combine authoritative maps with narrative text, images, and multimedia content.

\section{Determining paths and attractions suitable for sustainable tourism}

The use of sophisticated methods, primarily the production of various models of tourism development using the simulation, is becoming increasingly present in destination planning and management. New technologies in tourism development are imposing a growing need for the application of geographical information technologies in tourism, in order to meet the requirements of tourists in terms of the creation of the tourism product, and in relation 
to the choice of thedevelopment strategy whose implementation will ensure the sustainable development of tourism.

GIS can be used very efficiently in order to relieve the attractions from excessive tourist concentration. This is achieved by recording, digitizing and mapping the attributive attractions in the wider area of the primary indicative attractions. Maps with the aforementioned alternative tourist attractions and routes should be set in areas with a large number of tourists, but also in the vicinity of accommodation facilities, as well as in printed tour guides.

A large number of tourists can easily contribute to the degradation of the primary attractions. Therefore it's necessary to define the maximum carrying capacity of the attractions and to properly manage the number of tourists who are visiting them. On the other hand,a number of interesting attractions which have considerable potential but are not sufficiently valorized can be promoted in this manner.

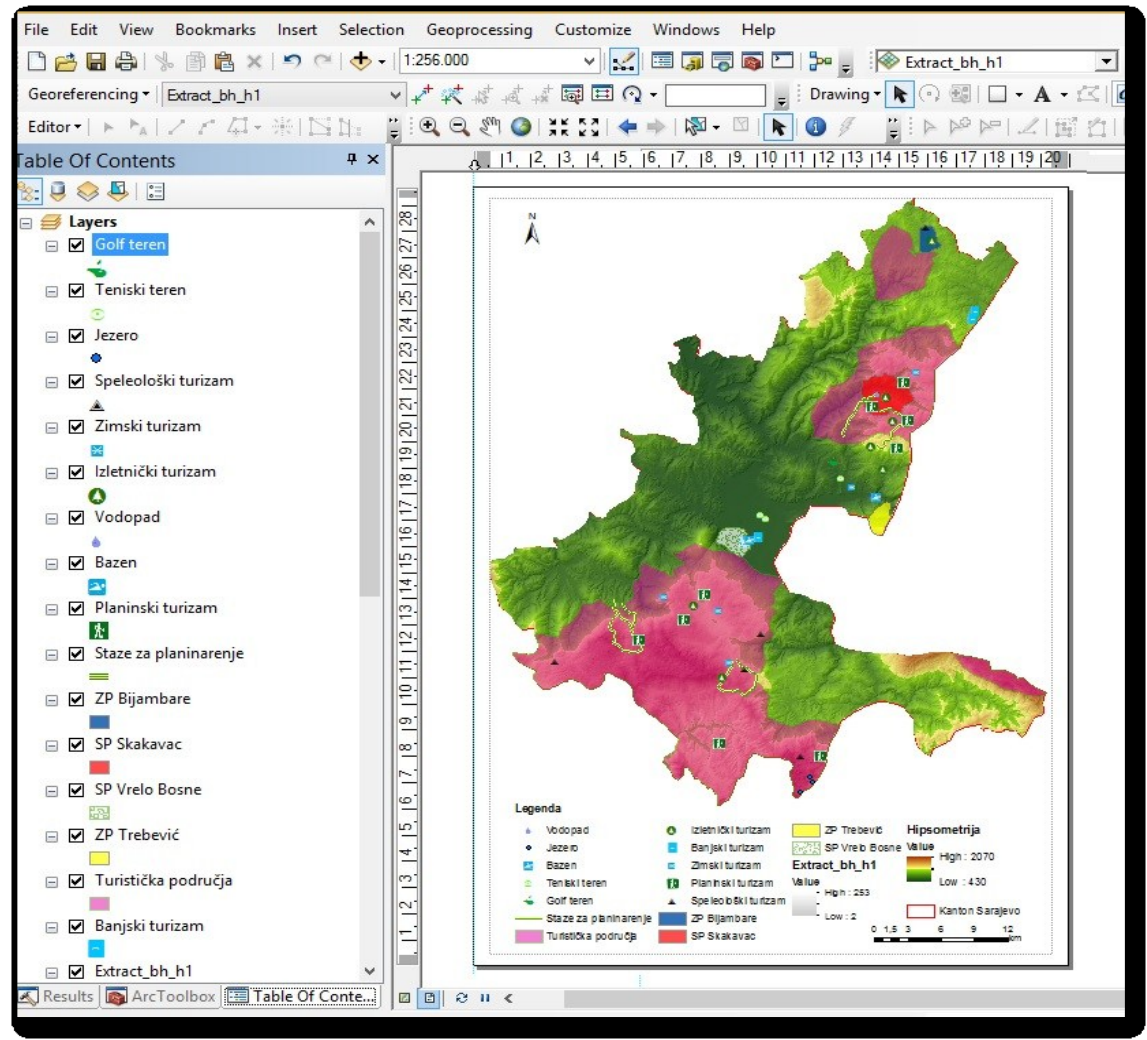

Fig. 4. Mapping the paths of sustainable tourism forms in Sarajevo Canton

Fig. 4. shows a map of the Sarajevo Canton, with the specified paths for hiking, caves, waterfalls, lakes, protected areas and other attractions in this area which are not sufficiently valorized. Using GIS provides their better involvement in tourism development, thus enabling a long-term survival of primary resource and the sustainable development of the entire destination. 


\section{CONCLUSION}

GIS has enormous potential for application in tourism which has not been sufficiently utilized. Currently the most important applications of GIS in tourism is related to the inventory of physical and socio-geographical tourism resources, and the calculation of the best routes and the shortest paths between two or more attractions. The possibility of the application of GIS to determine the most suitable areas for the building of new tourist accommodation facilities as well as for the construction of new attractions and / or the renovation of existing tourism infra and supra structure is so far underutilized, even though it has a large importance and potential. It is also important to emphasize the possibility of the application of GIS in the process of helping visitors to make a decision about traveling to a specific destination. This is particularly evident in the modern era of technology, where most decisions about taking trips happen through the promotion of a destination via internet portals. Beyond that, GIS facilitates the accessibility of the destination through navigation, but also by providing the ability for tourists to plan routes and to access information about accommodations, cultural events, weather conditions and other benefits provided by interactive maps as a result of the personal inquiries of tourists.

\section{REFERENCE LIST}

1. Baker, T. R. (no date). The History and Application of GIS in K-12 Education. Retrieved 27 May 2015 from http://www.gisdevelopment.net/Education/papers/edpa0003.htm

2. Baker, T. R. (2005). Internet-Based GIS Mapping in Support of K-12 Education. The ProfessionalGeographer, pp. 44-50. Oxford. Blackwell Publishing.

3. Baker, T. R. \&Bednarz, S. W. (2003). Lesson Learned from Reviewing Research in GIS Education.Journal of Geography, pp. 231-233, Washington. National Council for Geographic Education

4. Burrough, P.P., McDonnell, R.A. (1998). Principles of Geographical Information System. Oxford. Oxford University Press.

5. Davis, B. (1996). GIS: A Visual Approach. Santa Fe, Onward Press

6. Feick, R., Hall B. (2004). Sensitivity analysis of multi-criteria methods for site evaluation using a GIS decision support tool.International Journal of Geographic Information Science, pp. 815-840. Oxford. Taylor \& Francis

7. Hall, C.M. (2008). Tourism Planning: Policies, Processes and Relationships - 2nd ed. Essex. Pearson Education.

8. Mason P. (2003). Tourism impacts, planning and management, Burlington, Butterworth Heinemann

9. Neidhardt, T. (2004).Sarajevo kroz vrijeme, Sarajevo, Arka press

10. Pang, A. (2001). The Educational Effectiveness of Dynamic and Interactive Data Visualization and Exploration in Geographical Education. Masters Thesis, Department of Geography, Birkbeck College, University of London

11. Pobrić, A., Robinson M.G., Engelstoft S. (2004). "Débaptiser les rues de Sarajevo et l'identitébosniaque", L'Europe de l'Estquinzeans après la chute du mur, Des pays baltes à l'ex-Yougoslavie, pp. 325-330.Paris, L'Harmattan, collection Géographie et Cultures

12. Stynes D.J., O’Halloran C. (1987).Tourism Planning, Lansing, Michigan State University 